\section{Using simulated temperature regimes to test growth and development of an invasive forest insect under climate change}

Running title: Insect growth under simulated climate change

\begin{abstract}
Jonathan A. Walter ${ }^{1,2}$, Lily M. Thompson ${ }^{1,3}$, Sean D. Powers ${ }^{4}$, Dylan Parry ${ }^{5}$, Salvatore J.
\end{abstract} Agosta $^{6}$, Kristine L. Grayson ${ }^{1}$

${ }^{1}$ Department of Biology, University of Richmond, Richmond, VA 23173

${ }^{2}$ Department of Environmental Sciences, University of Virginia, Charlottesville, VA 22904

${ }^{3}$ Department of Forestry and Environmental Conservation, Clemson University, Clemson, SC 29634

${ }^{4}$ Integrative Life Sciences Doctoral Program, Virginia Commonwealth University, Richmond, VA 23284

${ }^{5}$ Department of Environmental Biology, SUNY College of Environmental Science and Forestry, Syracuse, NY 13210

${ }^{6}$ Center for Environmental Studies, Virginia Commonwealth University, Richmond, VA 23284

Corresponding author:

Jonathan Walter

Department of Environmental Sciences

University of Virginia

291 McCormick Rd

Box 400123

Charlottesville, VA 22904

jaw3es@virginia.edu

Data availability: Data and code accompanying this study will be publicly archived on Zenodo upon manuscript acceptance and the repository DOI provided in the final version. During review, these files are available on GitHub at https://github.com/jonathan-walter/ldclimate.

Keywords: Lymantria dispar, climate warming, growth chamber, local adaptation, physiology, reciprocal transplant 


\section{Abstract}

42 Temperature and its impact on fitness are fundamental for understanding range shifts and

43 population dynamics under climate change. Geographic climate heterogeneity, behavioural and

44 physiological plasticity, and thermal adaptation to local climates makes predicting the responses

45 of species to climate change complex. Using larvae from seven geographically distinct wild

46 populations in the eastern United States of the non-native forest pest Lymantria dispar dispar

47 (L.), we conducted a simulated reciprocal transplant experiment in environmental chambers

48 using six custom temperature regimes representing contemporary conditions near the southern

49 and northern extremes of the US invasion front and projections under two climate change

50 scenarios for the year 2050. Larval growth rates increased with climate warming compared to

51 current thermal regimes and responses differed by population. A significant population-by-

52 treatment interaction indicated that growth rates increased more when a source population

53 experienced the warming scenarios for their region, especially for southern populations. Our

54 study demonstrates the utility of simulating thermal regimes under climate change in

55 environmental chambers and emphasizes how the impacts from future increases in temperature

56 can be heterogeneous due to geographic differences in climate-related performance among

57 populations. 


\section{Introduction}

Climate change is altering the geographic ranges and population dynamics of organisms

62 across the globe (Parmesan \& Yohe, 2003; Thomas, 2010). Such changes reflect the accumulated

63 effects of a shifting climate on individual fitness. Similar to other ectothermic taxa, insects are

64 thought to be especially susceptible to direct effects of climate change due to the temperature-

65 dependence of their vital rates (Björkman et al., 2011; Boggs, 2016); however, whether the net

66 effects are positive or negative for population growth and viability can depend on contexts

67 including geography, species life history, and how climate change impacts species interactions

68 (Klapwijk et al., 2013; Van Dyck et al., 2015; Walter et al., 2018).

Numerous studies have quantified the physiological performance of various insect

70 species in response to temperature (e.g., Kingsolver and Woods 1997, Fischer et al. 2011).

71 However, two major caveats pertain to much of this work (Lindroth \& Raffa, 2017). First, these

72 studies often use constant-temperature thermal regimes to measure thermal performance (e.g.,

73 Thompson et al. 2017, von Schmalensee et al. 2021). Second, studies of insect response to

74 climate warming often increase temperature in the lab or field by a constant (e.g., $+2{ }^{\circ} \mathrm{C}$;

75 Bauerfeind and Fischer 2014, Rich, et al. 2015). Given that the effects of climate change on

76 temperature differ geographically (Karmalkar \& Bradley, 2017), seasonally (Kirk et al., 2019),

77 and diurnally (Braganza et al., 2004), such studies may provide an incomplete view of the

78 response of insects to climate change.

These shortcomings can be overcome through the combination of modern environmental

80 chambers and spatially downscaled climate projections including greenhouse gas forcing

81 scenarios adopted by the Intergovernmental Panel on Climate Change (IPCC), which have

82 relatively recently become publicly available (Eyring et al., 2016; Taylor et al., 2012). When 
83 coupled with environmental chambers capable of fine-scale temperature programming, these

84 projections can be used to experimentally simulate temperature treatments that more accurately

85 reflect temperature regimes found in nature. Other environmental factors potentially contributing

86 to changes in development and fitness (e.g., light, nutrient resources, water availability, air flow)

87 can be held constant in this type of growth chamber simulation, which allows for the effect of

88 future temperature regimes on development and fitness to be evaluated independently. Despite

89 its potential, however, this approach has been little used.

Lymantria dispar dispar (L.) (Lepidoptera: Erebidae; historical common name 'European

91 gypsy moth') is an invasive forest-defoliating generalist pest in North America that feeds on over

92300 host trees and causes an average of \$250M USD of economic damage in the US annually

93 (Aukema et al., 2011). Outbreaks of L. dispar have been implicated as a contributing factor to

94 the decline of oaks (Quercus spp.) in eastern North America (Morin \& Liebhold, 2016), and

95 defoliation events alter ecosystem processes (Clark et al., 2010; Riscassi \& Scanlon, 2009). Its

96 northern invasive range limit is bounded by lethal cold temperatures for overwintering eggs and

97 insufficient warmth to complete larval development within the shortened growing season (Gray,

98 2004; Streifel et al., 2019), while southern range limits may be governed by supraoptimal

99 temperatures and a lack of sufficient chilling necessary to terminate diapause in overwintering

100 eggs (Gray, 2004; Tobin et al., 2014). Consequently, the thermal performance of L. dispar under

101 climate change may influence the location, severity, and frequency of future population

102 outbreaks, and in turn, their cascading ecological and economic impacts.

103

Adding complexity to understanding the effects of climate change on L. dispar, recent

104 studies have found that ecologically important traits have adapted to local climates across the

105 invasion font. For example, egg masses sourced from warmer climates had higher viability when 
reared at warm range-edge temperatures relative to populations from cooler regions (Faske et al.,

107 2019). In constant temperature experiments, warmer climate populations had lower mortality

108 rates and smaller reductions in fitness-associated traits when reared at supraoptimal temperatures

109 than those sourced from cooler climates (Thompson et al., 2017, 2021). Additionally, genomic

110 evidence is consistent with a genetic basis for phenotypic differences in temperature-related

111 performance traits (Friedline et al., 2019). The detailed knowledge on the spread and thermal

112 performance of this invasive species makes it an ideal organism to investigate thermal

113 performance and fitness under realistic future temperature scenarios.

114 This study addresses the following questions: 1) how does L. dispar growth and

115 development respond to projected 2050 climatic conditions; and 2) does this response vary

116 among populations from different parts of its invasive range? We simulated climates near the

117 southern and northern extremes of the US invasion encompassing the larval growing season from

118 egg hatch to pupation and measured development in seven populations. We hypothesized that

119 climate warming would enhance fitness-related traits relative to a contemporary climate baseline

120 under northern range-edge thermal conditions, but would reduce performance under southern

121 range-edge conditions. Moreover, we hypothesized that the magnitude of these effects will

122 depend on source population due to a history of local adaptation to climate, with individuals

123 from cooler climates tending to perform better in cooler temperature regimes and individuals

124 from warmer climates being more tolerant of warming.

125

126 Methods

127 Experimental Design 
Individuals used in this experiment were sourced from seven populations in the Eastern

129 US, a subset of those used in Thompson et al. (2021). These populations represent areas of active range expansion and the current climatic extremes of the $L$. dispar invasive range in the US

131 (Figure 1a). Individuals used in this experiment were transported and housed under USDA APHIS permits P526P-17-03681 (KLG) and P526P-16-04388 (DP).

137 for which we generated thermal regimes (Figure 1a). These locations are near the inland north-

138 western and south-eastern extremes of the invasion front and represent extremes of cold and 139 warmth experienced by L. dispar in the USA. The CC4.5 and CC 8.5 designations correspond to 140 moderate and more severe representative concentration pathways, scenarios for future 141 greenhouse gas emissions that are used to drive climate projections.

143 Amant 2017) and represent the mean of 200 replicate simulations of daily minimum and

144 maximum temperatures. Baseline temperature regimes were based on 1981-2010 climate

145 normals, and climate change scenarios were based on the CanRCM4 climate model (Scinocca et 146 al., 2016). Simulated future temperature time series for each of the four nearest weather stations 147 were constructed by adjusting 1981-2010 normals with temperature anomalies from CanRCM4 148 projections. We aligned the start of each chamber simulation program to the predicted date of 149 median egg hatch as estimated using the L. dispar phenology model in BioSIM (Gray, 2004; 
150 Gray et al., 2001; Regniere \& Sharov, 1997). The experiment began by introducing newly

151 hatched larvae at the predicted hatch date for each simulation.

153 Scientific, Inc. model I-22VL running Intellus Connect Ultra software) on a ramp between a

154 daily minimum temperature at $7 \mathrm{am}$ and a daily maximum temperature at $9 \mathrm{pm}$. The chambers

155 maintained a 14 hour light, 10 hour dark cycle with lights on between 7am and 9pm. Humidity

156 ranged from $60-80 \%$. The positions of individuals within the chamber were rotated to prevent

157 micro-scale differences in air flow and light from having persistent effects on development.

158 Three treatments each were housed in labs at Virginia Commonwealth University

159 (Baseline VA, Baseline WI, CC4.5WI) and at University of Richmond (CC4.5VA, CC8.5VA,

$160 \mathrm{CC} 8.5 \mathrm{WI})$. Both labs used the same model of growth chamber with all settings in common. Prior

161 to the experiment, each environmental chamber was carefully calibrated for both light and dark

162 cycles using a two different ca. three-day programs to ensure each chamber maintained

163 temperature within a tolerance of $\pm 0.5^{\circ} \mathrm{C}$. In the first, temperature stepped from $6^{\circ} \mathrm{C}$ to $16^{\circ} \mathrm{C}$ to

$16426^{\circ} \mathrm{C}$. In the second, chambers were brough to a constant temperature over 8 hours before

165 implementing two daily cycles between low and high temperatures corresponding to the

166 beginning of the VA base temperature treatment. Temperature data loggers (HOBO U23 Pro v2,

167 Onset Computer Corporation) were also placed inside each environmental chamber to track

168 rearing temperatures across the experiment. These records showed that actual chamber

169 temperatures tracked programmed temperatures across treatments, with only minor deviations

170 that did not obscure differences among treatments (Figure S1). In addition, an earlier experiment

171 conducted in these environmental chambers replicated two different fluctuating temperature

172 thermal regimes in two chambers each, and found no differences in development times, masses, 
173 or survivorship between chambers implementing the same treatments (K. Grayson, unpublished

174 data).

175 Larvae were housed in individual plastic cups with cubes of artificial diet (USDA APHIS

176 formulation) that were replaced weekly. Individuals were checked daily between 10am and 2pm

177 for changes in developmental stage. We recorded the following: third instar date, third instar

178 mass, fifth instar date, fifth instar mass, pupation date, pupal mass, adult emergence date, and

179 sex. The sex of individuals could not be determined if they died prior to the sexual dimorphism

180 apparent in late stage larvae. We focus here on data from third and fifth instars because fungal

181 contamination of the artificial diet increased mortality between fifth instar and adulthood in

182 individuals raised in one of the laboratories (Figure S2). Data from this and a previous

183 experiment (Thompson et al., 2021) showed that larval masses were strongly correlated with

184 pupal masses (Table S1), which in turn, are an excellent proxy for fecundity (Faske et al., 2019;

185 Honěk, 1993).

186

187 Analyses

We analysed how growth rate from hatch to third and to fifth larval instars depended on

189 climate treatment (Baseline WI, Baseline VA, CC4.5 WI, CC4.5 VA, CC8.5 WI, CC8.5 VA),

190 source population (AL, IR, MN, NC1, NC2, WI1, WV1; see Figure 1), and the interaction

191 between treatment and source population. Growth rates were computed as the difference from

192 neonate mass divided by the development time, expressed in $\mathrm{g} \mathrm{day}^{-1}$. Because individual neonate

193 masses were below the precision of standard analytical balances, we weighed 5 replicate groups

194 of 5 neonate larvae from each source population and took the average mass of an individual

195 neonate larva. We included a random effect of individual sex (i.e., male, female, unknown) on 
196 the intercept because $L$. dispar become sexually dimorphic later in development. Individuals that

197 did not survive long enough to visually determine sex (sex = unknown) were grouped together.

198 Given that the experiments were conducted within high performance environmental chambers

199 housed within modern climate-controlled laboratories in close geographical proximity, it is

200 unlikely that a meaningful laboratory effect occurred, but we cannot rule it out. Analyses were

201 conducted using linear mixed effects models with the 'ImerTest' package (Kuznetsova et al.,

202 2017) in R version 3.6.1 (R Core Team, 2020). Significance of model terms was assessed using

203 Wald $X^{2}$ tests with type-III sums of squares. Post-hoc comparisons between groups were

204 considered to be significantly different based on $95 \%$ confidence intervals of estimated marginal

205 means.

206

207 Results

208 The effects of temperature regime treatment, population and treatment-by-population

209 interaction on larval growth rates were consistent between third and fifth instars. We focus on

210 results for fifth instars; parallel results for third instars are shown in Figure S3. Growth rates of

211 fifth instar larvae differed by treatment $\left(d f=5, X^{2}=883.5, p<0.0001\right)$ and population $\left(d f=6, X^{2}\right.$

$212=301.0, p<0.0001)$, with a statistically significant two-way interaction between treatment and

213 population $\left(d f=30, X^{2}=89.2, p<0.0001\right)$. Growth rates to fifth instar tended to increase in

214 simulated climate change treatments (Figure 2a), and were highest in the CC4.5WI, CC8.5WI,

215 and CC8.5VA treatments. Larvae from the WI and MN source populations tended to grow more

216 slowly than those from other source populations (Figure 2b). The treatment-by-population

217 interaction effect suggests that L. dispar larvae tend to respond to climate warming by increasing

218 growth rate more so in simulated future climates that represented the region from where they 
were sourced (Figure 2c). For example, the fastest-growing populations in the CC8.5WI treatment were the two northernmost source populations, while the fastest-growing populations

221 in the CC8.5VA treatment were the three populations from the southern range boundary.

223 Discussion

Our study of $L$. dispar development under contemporary and future thermal regimes

225 predicts that future larval growth rates of this destructive insect pest depend on both the degree

226 of climate warming and geography. In general, our results suggest that larval growth rates could

227 increase across the invasive range under climate warming based on the performance of

228 caterpillars from different populations under simulated future thermal regimes. As hypothesized,

229 warming increased growth rates at the northern range edge, but contrary to expectations warming

230 did not make conditions at the southern range boundary too hot for development. Taking larval

231 growth rates as an index of fitness due to the correlation between mass and fecundity (Faske et

232 al., 2019) and the reduction in exposure time to natural enemies from more rapid growth, our

233 findings suggest that, given sufficient host plant resources, future changes in fitness will depend

234 on the population location and magnitude of temperature change. If climate warming causes

235 geographically dependent trends in L. dispar fitness, there would be substantial effects on the

236 future ecological and economic impacts of this forest pest, and on allocation of management

237 efforts to slow its spread.

238 We found evidence that source populations responded differently to experimental 239 treatments (Figure 2c). However, evidence for local adaptation of larval growth and development

240 was equivocal overall, in contrast to other recent studies (Faske et al., 2019; Friedline et al.,

241 2019; Thompson et al., 2017, 2021). Among-population variation in larval growth rates in the 
242 baseline and CC4.5 treatments was not discernibly related to a "home field advantage" as was

243 seen in the CC8.5 treatments. One possibility is that only in the CC8.5 treatments did

244 supraoptimal temperatures occur frequently enough during larval development for growth rates

245 to diverge. Studies testing thermal performance under constant temperatures may be more likely

246 to see population variation in responses to thermal extremes, while this experiment used

247 fluctuating regimes in which supraoptimal temperatures were transient, even under climate

248 change treatments. There is evidence that southern populations are more tolerant of high

249 temperatures (Thompson et al., 2017, 2021), which could explain their better performance in our

250 hottest treatments. However, we found no clear evidence that northern populations can perform

251 better than southern populations in a colder climate (Figure 2c). Overall, these results continue to

252 demonstrate that while larval growth and development in L. dispar has undergone climate-

253 related adaptation, these traits remain plastic in response to temperature (Thompson et al. 2021).

254 Future L. dispar performance with climate warming could make range expansion and

255 population outbreaks more common in the northern range extremes. Indeed, establishment of

256 populations in northern Minnesota has occurred in areas predicted to be marginal for survival

257 (Streifel et al., 2019). Conversely, at the southern extreme, range stasis and retraction has already

258 been observed (Tobin et al., 2014) but our results suggest that larval development at the southern

259 range edge is not impaired by present or projected future temperature regimes. Reduced egg

260 viability, possibly due to insufficient cold to complete diapause, could be the mechanism for

261 range stasis at the southern extreme (Faske et al., 2019; Gray, 2004). More broadly, our predicted

262 effects could be amplified or negated by effects of climate change on life stages not considered

263 in this study (Kingsolver \& Buckley, 2020), or by effects on ecological relationships, e.g., with

264 host plants or natural enemies. Geographical changes in the propensity for range expansion and 
population outbreaks would be of considerable concern to extensive management efforts to slow spread and protect land from damaging outbreaks (Tobin et al., 2012).

The ability to test experimental thermal regimes featuring spatially explicit climate

268 change projections was an innovative approach that greatly enhanced the realism of this study

269 while retaining the ability afforded by environmental chambers to maintain consistency in

270 unmanipulated conditions. As climate change has non-uniform effects on the spatiotemporal

271 distributions of temperatures (Braganza et al., 2004; Karmalkar \& Bradley, 2017; Kirk et al.,

272 2019), our approach represents a substantial advance in methodology compared to simply

273 increasing temperature by a constant value from a current baseline. Additionally, programmed

274 environmental chambers provide the ability to test realistic thermal regimes from any geographic

275 position or point in time independent of physical location. We are unaware of other studies

276 taking this approach, likely in part because its feasibility depends on modern environmental

277 chamber control software and a study system with some a priori knowledge of phenology, but

278 we encourage this design as a means of increasing the realism of climate change ecophysiology

279 studies in controlled experimental settings.

280 A robust body of literature on insects has shown that warmer temperatures can facilitate

281 range expansion (Lehmann et al., 2020) or can accelerate invasion speed (Seiter \& Kingsolver,

282 2013), but may also negatively impact populations of other species (Haynes et al., 2014; Johnson

283 et al., 2010; Klapwijk et al., 2013). Such variations in thermal responses impede generalization

284 of the response of species to climate change. Our findings, taken together with other studies

285 documenting geographical variation in thermal response of $L$. dispar (Faske et al., 2019;

286 Thompson et al., 2017, 2021), emphasize how the ecological effects of climate change can be

287 spatially heterogeneous, not only due to regional variation in climate change (Karmalkar \& 
Bradley, 2017), but also due to variation in the thermal tolerance and performance of local populations of a given species.

\section{Acknowledgements}

292 This work was supported by the National Science Foundation (DEB 1702701), the Slow the

293 Spread Foundation (DP and KG), the University of Richmond School of Arts \& Sciences, and

294 the Virginia Commonwealth University Center for Environmental Studies. Remi Saint-Amant

295 generated temperature time series. T. Faske, C. Jahant-Miller, K. Onufrieva, C. Foelker, K.

296 Theilen-Cremers, C. Elder, J. Johnson, S. Hoffman, C.J. Campbell and V. Huelsman helped

297 acquire source material for this study. S. Goetz and C. Jahant-Miller assisted in maintaining

298 population cultures. K. Sanchez, R. Ostrom, C. Miller, P. Hafker, A. Burnett, L. Milner, and P.

299 Gibbs helped rear larvae and collect data.

\section{References}

302 Aukema, J. E., Leung, B., Kovacs, K., Chivers, C., Britton, K. O., Englin, J., Frankel, S. J., 303 Haight, R. G., Holmes, T. P., Liebhold, A. M., McCullough, D. G., \& Von Holle, B. (2011). Economic impacts of non-native forest insects in the continental United States. PLoS ONE, 6(9), e24587. https://doi.org/10.1371/journal.pone.0024587 not means diminish performance in a widespread butterfly. Population Ecology, 56(1), 
Björkman, C., Bylund, H., Klapwijk, M. J., Kollberg, I., \& Schroeder, M. (2011). Insect pests in future forests: More severe problems? Forests, 2(2), 474-485. https://doi.org/10.3390/f2020474

Boggs, C. L. (2016). The fingerprints of global climate change on insect populations. Current Opinion in Insect Science, 17, 69-73.

Braganza, K., Karoly, D. J., \& Arblaster, J. M. (2004). Diurnal temperature range as an index of global climate change during the twentieth century. Geophysical Research Letters, 31(13), L13217. https://doi.org/10.1029/2004GL019998

Clark, K. L., Skowronski, N., \& Hom, J. (2010). Invasive insects impact forest carbon dynamics. Global Change Biology, 16(1), 88-101. https://doi.org/10.1111/j.13652486.2009.01983.x

Eyring, V., Bony, S., Meehl, G. A., Senior, C. A., Stevens, B., Stouffer, R. J., \& Taylor, K. E. (2016). Overview of the Coupled Model Intercomparison Project Phase 6 (CMIP6) experimental design and organization. Geoscientific Model Development, 9(5), 19371958. https://doi.org/10.5194/gmd-9-1937-2016

Faske, T. M., Thompson, L. M., Banahene, N., Levorse, A., Quiroga Herrera, M., Sherman, K., Timko, S. E., Yang, B., Gray, D. R., Parry, D., Tobin, P. C., Eckert, A. J., Johnson, D. M., \& Grayson, K. L. (2019). Can gypsy moth stand the heat? A reciprocal transplant experiments: Is the use of constant rather than fluctuating temperatures justified when 
investigating temperature-induced plasticity? Oecologia, 166(1), 23-33.

Friedline, C. J., Faske, T. M., Lind, B. M., Hobson, E. M., Parry, D., Dyer, R. J., Johnson, D. M., Thompson, L. M., Grayson, K. L., \& Eckert, A. J. (2019). Evolutionary genomics of gypsy moth populations sampled along a latitudinal gradient. Molecular Ecology, mec.15069. https://doi.org/10.1111/mec.15069

Gray, D. R. (2004). The gypsy moth life stage model: Landscape-wide estimates of gypsy moth establishment using a multi-generational phenology model. Ecological Modelling, 176(12), 155-171. https://doi.org/10.1016/j.ecolmodel.2003.11.010

Gray, D. R., Ravlin, F. W., \& Braine, J. A. (2001). Diapause in the gypsy moth: A model of inhibition and development. Journal of Insect Physiology, 47(2), 173-184.

Haynes, K. J., Allstadt, A. J., \& Klimetzek, D. (2014). Forest defoliator outbreaks under climate https://doi.org/10.1016/S0022-1910(00)00103-7 change: Effects on the frequency and severity of outbreaks of five pine insect pests.

346 Honěk, A. (1993). Intraspecific variation in body size and fecundity in insects: A general relationship. Oikos, 66(3), 483. https://doi.org/10.2307/3544943

348 Johnson, D. M., Buntgen, U., Frank, D. C., Kausrud, K., Haynes, K. J., Liebhold, A. M., Esper, 349 J., \& Stenseth, N. C. (2010). Climatic warming disrupts recurrent Alpine insect outbreaks. Proceedings of the National Academy of Sciences, 107(47), 20576-20581. https://doi.org/10.1073/pnas.1010270107 
352

353

354

355

356

357

358

Karmalkar, A. V., \& Bradley, R. S. (2017). Consequences of global warming of $1.5^{\circ} \mathrm{C}$ and $2{ }^{\circ} \mathrm{C}$ for regional temperature and precipitation changes in the contiguous United States. PLOS ONE, 12(1), e0168697. https://doi.org/10.1371/journal.pone.0168697

Kingsolver, J. G., \& Buckley, L. B. (2020). Ontogenetic variation in thermal sensitivity shapes insect ecological responses to climate change. Current Opinion in Insect Science, 41, 1724. https://doi.org/10.1016/j.cois.2020.05.005

Kingsolver, J. G., \& Woods, H. A. (1997). Thermal sensitivity of growth and feeding in Manduca sexta caterpillars. Physiological Zoology, 70(6), 631-638. https://doi.org/10.1086/515872

Kirk, M. A., Galatowitsch, M. L., \& Wissinger, S. A. (2019). Seasonal differences in climate change explain a lack of multi-decadal shifts in population characteristics of a pond breeding salamander. PLOS ONE, 14(9), e0222097. https://doi.org/10.1371/journal.pone.0222097

Klapwijk, M. J., Csóka, G., Hirka, A., \& Björkman, C. (2013). Forest insects and climate change: Long-term trends in herbivore damage. Ecology and Evolution, 3(12), 41834196. https://doi.org/10.1002/ece3.717

Kuznetsova, A., Brockhoff, P. B., \& Christensen, R. H. B. (2017). lmerTest package: Tests in linear mixed effects models. Journal of Statistical Software, 82(13). https://doi.org/10.18637/jss.v082.i13

Lehmann, P., Ammunét, T., Barton, M., Battisti, A., Eigenbrode, S. D., Jepsen, J. U., Kalinkat, G., Neuvonen, S., Niemelä, P., Terblanche, J. S., Økland, B., \& Björkman, C. (2020). Complex responses of global insect pests to climate warming. Frontiers in Ecology and the Environment, fee.2160. https://doi.org/10.1002/fee.2160 
375 Lindroth, R. L., \& Raffa, K. F. (2017). Experimental approaches for assessing invertebrate

376

377

378

379

380

381 responses to global change factors. In S. N. Johnson \& T. H. Jones (Eds.), Global Climate Change and Terrestrial Invertebrates (pp. 30-45). John Wiley \& Sons, Inc.

Morin, R. S., \& Liebhold, A. M. (2016). Invasive forest defoliator contributes to the impending downward trend of oak dominance in eastern North America. Forestry, 89(3), 284-289. https://doi.org/10.1093/forestry/cpv053

Parmesan, C., \& Yohe, G. (2003). A globally coherent fingerprint of climate change impacts across natural systems. Nature, 421(6918), 37-42. https://doi.org/10.1038/nature01286

R Core Team. (2020). R: A language and environment for statistical computing (4.0.3) [Computer software]. https://www.R-project.org/

Regniere, J., \& Saint-Amant, R. (2017). BioSIM (Version 10) [Computer software]. https://cfs.nrcan.gc.ca/projects/133

Regniere, J., \& Sharov, A. (1997). Forecasting gypsy moth flight in the northeastern US with BioSIM. Integrating Spatial Information Technologies for Tomorrow, 99-103.

Rich, R. L., Stefanski, A., Montgomery, R. A., Hobbie, S. E., Kimball, B. A., \& Reich, P. B. (2015). Design and performance of combined infrared canopy and belowground warming in the B4WarmED (Boreal Forest Warming at an Ecotone in Danger) experiment. Global Change Biology, 21, 2334-2348.

Riscassi, A. L., \& Scanlon, T. M. (2009). Nitrate variability in hydrological flow paths for three mid-Appalachian forested watersheds following a large-scale defoliation. Journal of Geophysical Research: Biogeosciences, 114(G2), G02009. https://doi.org/10.1029/2008JG000860 
Scinocca, J. F., Kharin, V. V., Jiao, Y., Qian, M. W., Lazare, M., Solheim, L., Flato, G. M., Biner, S., Desgagne, M., \& Dugas, B. (2016). Coordinated global and regional climate modeling. Journal of Climate, 29(1), 17-35. https://doi.org/10.1175/JCLI-D-15-0161.1

Seiter, S., \& Kingsolver, J. (2013). Environmental determinants of population divergence in lifehistory traits for an invasive species: Climate, seasonality and natural enemies. Journal of Evolutionary Biology, 26(8), 1634-1645. https://doi.org/10.1111/jeb.12159 North America despite low predicted climatic suitability. Journal of Biogeography, 46(1), 58-69. https://doi.org/10.1111/jbi.13474

Taylor, K. E., Stouffer, R. J., \& Meehl, G. A. (2012). An overview of CMIP5 and the experiment design. Bulletin of the American Meteorological Society, 93(4), 485-498. https://doi.org/10.1175/BAMS-D-11-00094.1 Distributions, 16, 488-495.

412 Thompson, L. M., Faske, T. M., Banahene, N., Grim, D., Agosta, S. J., Parry, D., Tobin, P. C., Johnson, D. M., \& Grayson, K. L. (2017). Variation in growth and developmental responses to supraoptimal temperatures near latitudinal range limits of gypsy moth Lymantria dispar (L.), an expanding invasive species: Geographical variation in heat tolerance. Physiological Entomology, 42(2), 181-190. https://doi.org/10.1111/phen.12190

Thompson, L. M., Powers, S. D., Appolon, A., Hafker, P., Milner, L., Parry, D., Agosta, S. J., \& Grayson, K. L. (2021). Climate-related geographical variation in performance traits 
across the invasion front of a widespread non-native insect. Journal of Biogeography,

422 Tobin, P. C., Bai, B. B., Eggen, D. A., \& Leonard, D. S. (2012). The ecology, geopolitics, and economics of managing Lymantria dispar in the United States. International Journal of Pest Management, 58(3), 195-210. https://doi.org/10.1080/09670874.2011.647836

425 Tobin, P. C., Gray, D. R., \& Liebhold, A. M. (2014). Supraoptimal temperatures influence the range dynamics of a non-native insect. Diversity and Distributions, 20(7), 813-823. https://doi.org/10.1111/ddi.12197

Van Dyck, H., Bonte, D., Puls, R., Gotthard, K., \& Maes, D. (2015). The lost generation hypothesis: Could climate change drive ectotherms into a developmental trap? Oikos,

435 Walter, J. A., Ives, A. R., Tooker, J. F., \& Johnson, D. M. (2018). Life history and habitat explain variation among insect pest populations subject to global change. Ecosphere, 9(5), e02274. https://doi.org/10.1002/ecs2.2274 


\section{Figures}

a)

441

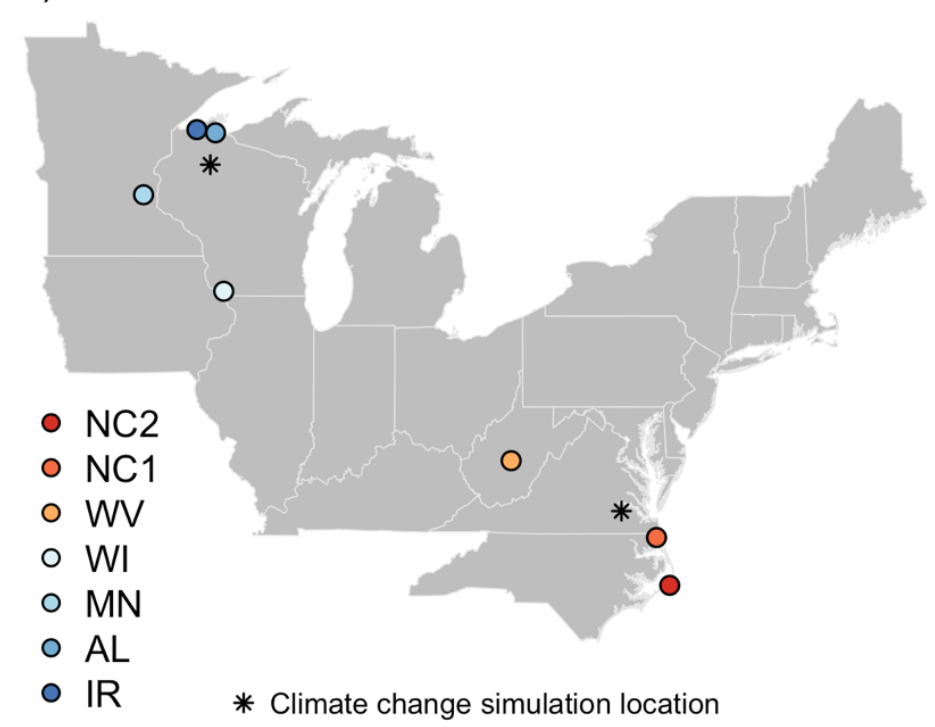

442 Figure 1. a) Map of L. dispar source populations. The order from south to north also corresponds

443 to the order of mean annual temperature at each source population location; b) Daily maximum

444 temperature over time for simulated temperature treatments, for the time period spanning

445 modelled egg hatch through adult emergence. The grey horizontal line indicates the thermal

446 optimum for L. dispar larval development $\left(29^{\circ} \mathrm{C}\right)$. Diamonds indicate empirical $95^{\text {th }}$ percentile

$4475^{\text {th }}$ instar maturation dates from this experiment. Projected climate change (respectively, RCP4.5

448 and RCP 8.5) increased mean daily maximum temperatures during development relative to their

449 historical baselines by $1.78^{\circ} \mathrm{C}$ and $4.38^{\circ} \mathrm{C}$ in Virginia and by $2.51^{\circ} \mathrm{C}$ and $4.87^{\circ} \mathrm{C}$ in Wisconsin.

450 Mean daily minimum temperatures increased by $2.07^{\circ} \mathrm{C}$ and $4.54^{\circ} \mathrm{C}$ in Virginia and by $2.58^{\circ} \mathrm{C}$

451 and $4.70^{\circ} \mathrm{C}$ in Wisconsin. 


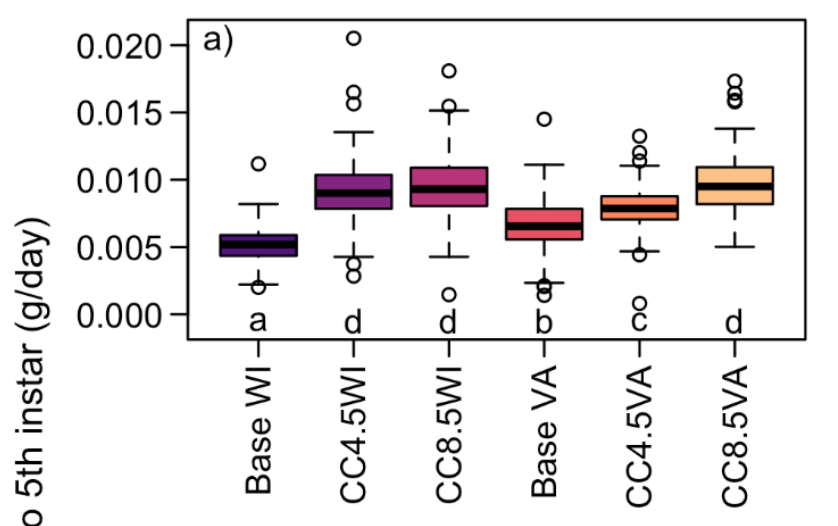

옹

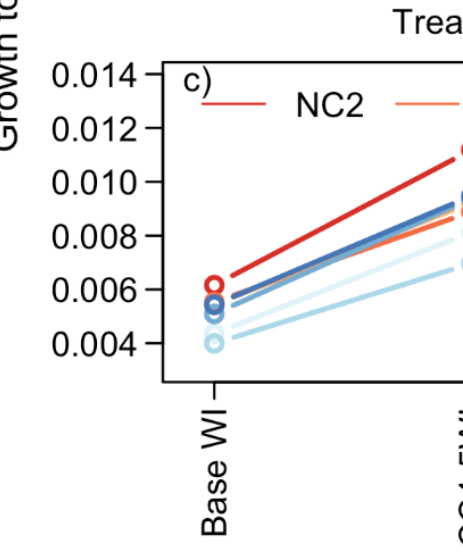

454 Figure 2. Fifth instar L. dispar larval masses by a) treatment, b) population, and c)

455 population $\times$ treatment interaction for all individuals. Treatments are ordered from coolest to

456 warmest. Populations are ordered from southernmost to northernmost. Lowercase letters in

457 panels a) and b) denote groups whose elements have estimated marginal means with overlapping

$45895 \%$ confidence intervals. Sex was included in statistical models as a random effect. 


\section{Online Supplement to: Simulated climate change alters thermal performance and expected fitness of a forest pest}

Jonathan A. Walter, Lily M. Thompson, Sean Powers ${ }^{4}$, Dylan Parry, Salvatore J. Agosta, Kristine L. Grayson

Correspondence: Jonathan Walter, jaw3es@virginia.edu

Table S1. Correlations between larval and pupal masses. Correlations are separated by sex due to sexual dimorphism. Data are taken from this study and from Thompson et al. (2021), which used constant temperature thermal regimes.

\begin{tabular}{|l|c|c|c|c|c|}
\hline \multicolumn{1}{|c|}{ Study } & Instar & Sex & $\boldsymbol{n}$ & $\hat{\boldsymbol{\rho}}$ & $\boldsymbol{p}$ \\
\hline This study & $3^{\text {rd }}$ & $\mathrm{M}$ & 358 & 0.11 & 0.037 \\
\hline This study & $3^{\text {rd }}$ & $\mathrm{F}$ & 272 & 0.07 & 0.075 \\
\hline This study & $5^{\text {th }}$ & $\mathrm{M}$ & 354 & 0.30 & $<0.001$ \\
\hline This study & $5^{\text {th }}$ & $\mathrm{F}$ & 266 & 0.37 & $<0.001$ \\
\hline Thompson et al. (2021) & $3^{\text {rd }}$ & $\mathrm{M}$ & 557 & 0.37 & $<0.001$ \\
\hline Thompson et al. (2021) & $3^{\text {rd }}$ & F & 475 & 0.13 & 0.004 \\
\hline
\end{tabular}



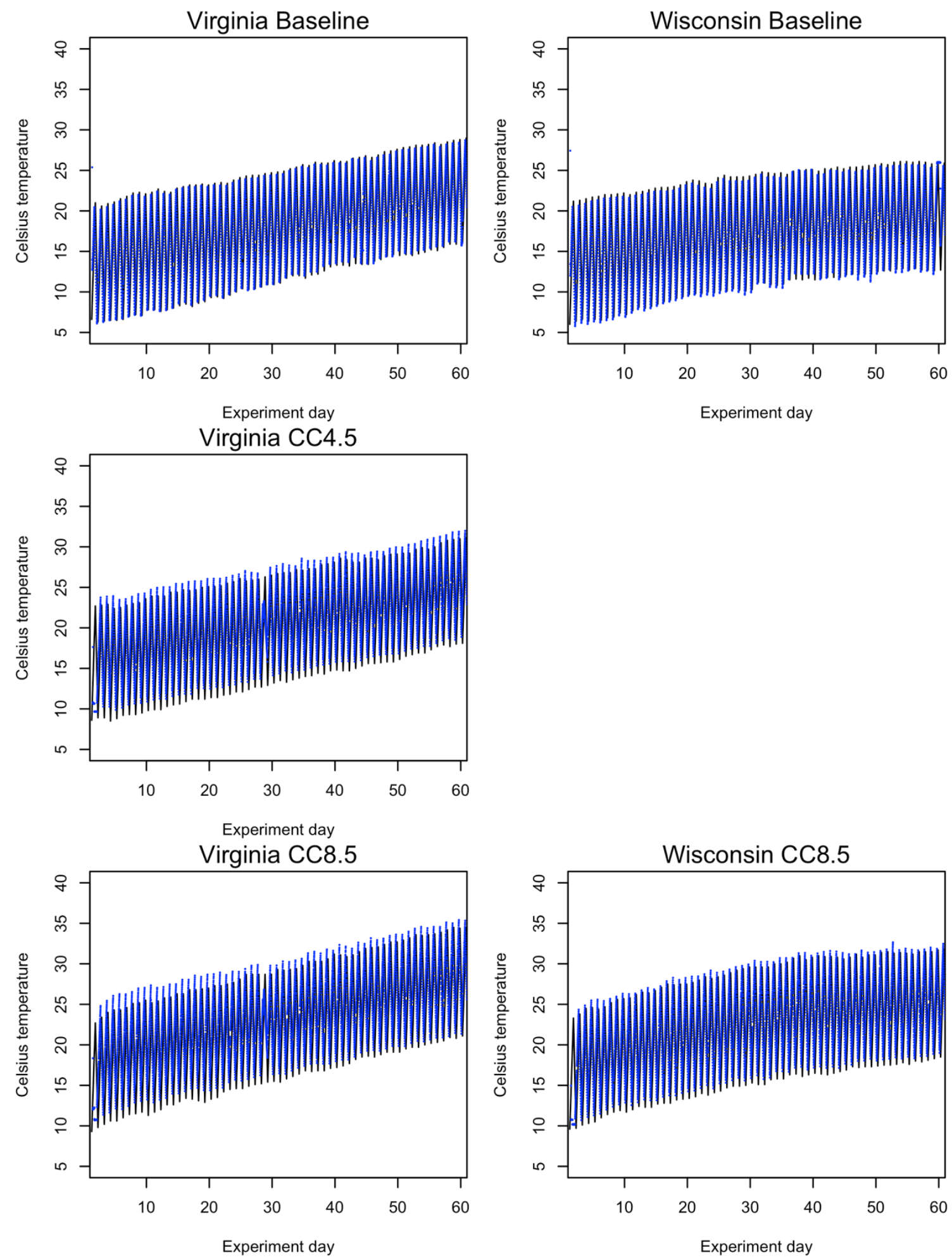

Figure S1. Comparison between environmental chamber programmed temperature (black lines) and recorded temperature (blue points). Wisconsin CC4.5 is not shown because the sensor failed to record data. By day 60 , every surviving larva had reached $5^{\text {th }}$ instar so the $\mathrm{x}$-axis is limited to days 1 through 60 . 


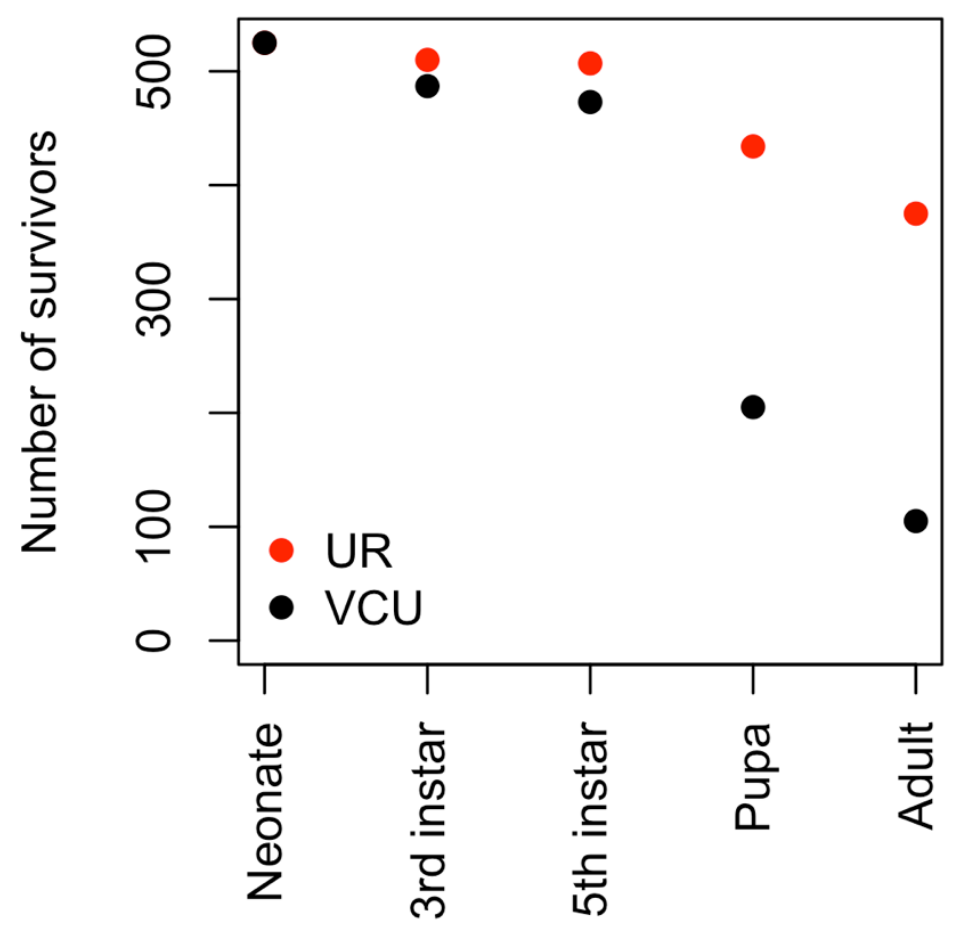

Figure S2. Number of survivors by life stage and laboratory. Larvae were introduced into environmental chambers as neonates and monitored for development into $3^{\text {rd }}$ and $5^{\text {th }}$ larval instars, pupae, and adults. A mold outbreak in the VCU laboratory caused apparent reductions in survival between $5^{\text {th }}$ instar and pupation, analyses presented in this manuscript focus on data for larvae. 


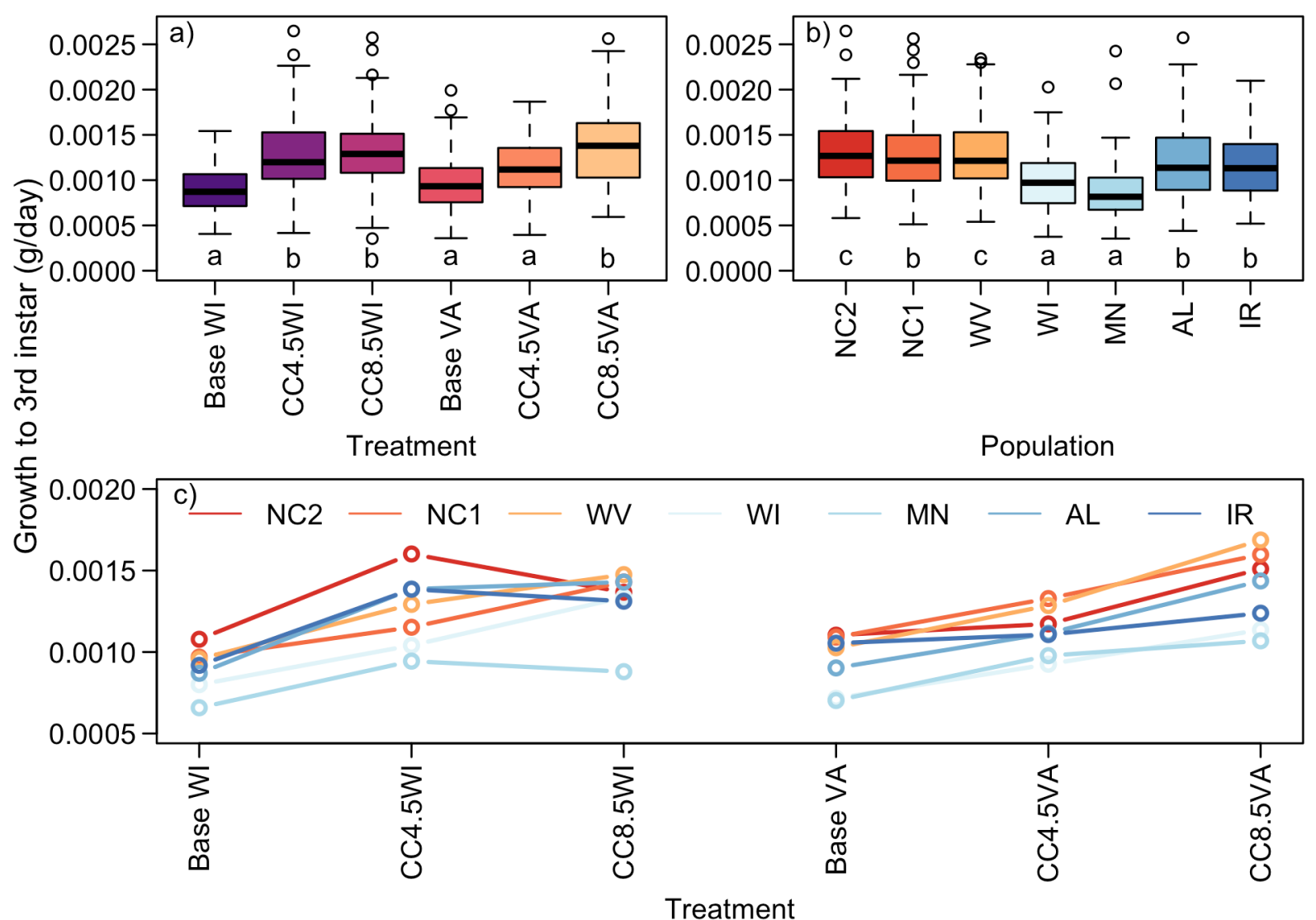

Figure S3. Third instar larval masses by a) treatment ( $\left.\mathrm{df}=5, X^{2}=349.47, p<0.0001\right)$, b)

population $\left(\mathrm{df}=6, X^{2}=251.031, p<0.0001\right)$, and c) population $\times$ treatment interaction $(\mathrm{df}=30$, $\left.X^{2}=92.16, p<0.0001\right)$ for all individuals. Treatments are ordered from coolest to warmest.

Populations are ordered from southernmost to northernmost. Lowercase letters in panels a) and b) denote groups whose elements have estimated marginal means with overlapping 95\% confidence intervals. Sex was included in statistical models as a random effect. 